Open Access

\title{
Dietary practices among individuals with diabetes and hypertension are similar to those of healthy people: a population-based study
}

Silvia Gl Ozcariz*, Carla de O Bernardo', Francieli Cembranel ${ }^{1}$, Marco A Peres ${ }^{2}$ and David A González-Chica ${ }^{1,3}$

\begin{abstract}
Background: Currently, diabetes mellitus (DM) and systemic arterial hypertension (SAH) are among the top five global risks for mortality. Among the modifiable factors, careful dietary practice is one of the essential elements for the control of NCDs, since these diseases are often the result of unhealthy lifestyles. Thus, this study aimed to assess the frequency of dietary practices among adult males and females with DM and/or SAH, and compare whether or not they are more frequent than in healthy adults, through a population-based study conducted in the city of Florianópolis, southern Brazil.
\end{abstract}

Methods: Cross-sectional population-based study, using as exposure self-reported DM and/or SAH status. Dietary practices were assessed using a semiquantitative food consumption questionnaire. The following were considered as adequate: regular intake ( $\geq 6$ times/week) of fruit and vegetables, daily intake of fruit ( $\geq 3$ times/day) and vegetables ( $\geq 2$ times/day), intake lower than 2 times/week of meat fat, fried foods, and soda. Bivariate and adjusted analysis for sociodemographic variables were conducted using Poisson regression, stratified by gender.

Location: Florianópolis, southern Brazil, 2009.

Subjects: Representative sample of 20 to 59 year-old adults ( $n=1720)$.

Results: A total of $16.6 \%$ participants were diagnosed with DM and/or SAH. The most frequently consumed unhealthy foods were fried food (51.0\%, 95\% Cl: 48.8-53.5) and soda (57.9\% 95\%Cl: 55.5-60.2). Of healthy foods, fruit was the less consumed on a daily basis (11.1\% 95\%Cl 9.6-12.5). In general, women showed better dietary practices than men. In adjusted analysis none of dietary practices was more frequent among diabetic and/or hypertensive adults compared with healthy individuals, regardless of gender. No differences were found between healthy and unhealthy adults, when the number of dietary practices was assessed.

Conclusions: The frequency of dietary practices was low and did not differ between individuals with or without $\mathrm{DM}$ and/or SAH. It is fundamental to reinforce the need of healthy dietary practices as one of the essential elements for the control of chronic diseases and their complications.

\footnotetext{
* Correspondence: silvia.ozcariz@gmail.com

${ }^{1}$ Post-Graduate Program in Public Health, Federal University of Santa

Catarina, 88040-970 Florianópolis, SC, Brazil

Full list of author information is available at the end of the article
} 


\section{Background}

Since the 1970s, Brazil has followed the global trend of demographic, nutritional, and epidemiological transition, which has caused major changes in the pattern of disease occurrence in the population. These processes have brought along an increased prevalence of overweight [1] and non-communicable diseases (NCDs), especially diabetes mellitus (DM) and systemic arterial hypertension (SAH) [1].

DM is a major growing public health problem [2]. In 2012, the World Health Organization (WHO) reported that, according to estimates and in a worldwide range, one in ten adults carries DM [3] (mostly type 2), and this number will double by 2025 [4]. In Brazil, it is estimated that $5.6 \%$ of the population over 18 years old has been diagnosed with this disease [5]. SAH is another major chronic illness, and it is one of the most frequent health problems nowadays [3]. SAH has increasingly reached more people, and it is estimated to affect one in three people over 18 years of age worldwide [3]. The prevalence of SAH among adults in Brazil ranges from 22.3\% to 43.9\% [6]. These values are similar to high-income countries, such as the United States, where in 2008 the prevalence was estimated in 34\% in adults [7].

Currently, DM and SAH are among the top five global risks for mortality [3]. Because DM and SAH are chronic diseases with severe complications and are difficult to control, they end up being costly for the individual, their families and for health services [8]. In Brazil, these two NCDs are responsible for the largest share of hospital care costs in the National Health System [9-11].

The treatment of these diseases includes not only drug intervention, but mostly a change in lifestyle. Among the modifiable factors, careful dietary practice is one of the essential elements for the control of NCDs, since these diseases are often the result of unhealthy lifestyles. WHO data indicates that about $80 \%$ of DM and SAH cases could be avoided through the adoption of dietary practices, such as regular consumption of fruit and vegetables, reduced consumption of saturated fats, sodium and sugary drinks, as well as increased physical activity and control of smoking habits [12]. Faced with such evidence, secondary prevention is essential, since it can positively change the evolutionary history of these problems, improving prognosis, life expectancy and quality $[2,13]$. However, success in controlling these diseases depends on adequate knowledge and patient decision to change his lifestyle [14]. In the United States, the National Health and Nutrition Examination Survey (NHANES) [15] investigated nearly 6,000 people from 2003 to 2004 and 2005 to 2006, and found no difference in the dietary practices of people with or without DM and/or SAH. In Brazil, it was not found any population based study in the scientific literature assessing if dietary practices are more common among people diagnosed with these NCDs. This kind of information is essential for the health planning of middle-income countries, such as Brazil, considering the quick process of nutritional and epidemiological transition they go through.

Thus, this study aimed to assess the frequency of healthy and unhealthy dietary practices among adult males and females with DM and/or SAH, and compare whether or not they are more frequent than in healthy adults, through a population-based study conducted in the city of Florianópolis, southern Brazil.

\section{Methods}

Cross-sectional population-based study conducted with a representative sample of adults living in the city of Florianópolis, capital of the state of Santa Catarina, southern Brazil. The estimated population in 2009 was 408,161 inhabitants [16], and the city had a human development index of 0.847 in 2010 (third best in Brazil) [17].

The results of this paper are part of the EpiFloripa Adulto survey, conducted from September 2009 to January 2010. This survey investigated several general and oral health conditions, anthropometry, habits and usage of health services in a representative sample of the 249,530 20-59 year-old adults living in the urban area of Florianópolis [16].

The sampling process was performed in two phases. Initially, 60 of the 420 census sectors of Florianopolis were drawn. The number of households in each one of the census sectors was updated. Then 18 households were selected in each of the sectors, aiming to reach the expected size of the sample $(n=2016)$. Data collection was undertaken by trained interviewers from September 2009 to January 2010. Personal Digital Assistants were used to apply face-to face interviews. More details about sampling process and inclusion/exclusion criteria can be assessed elsewhere [18].

Quality of the information was evaluated by phone calls to approximately $15 \%$ of the sample $(n=248)$, applying a reduced questionnaire consisting of 10 questions. Kappa values and intra-class correlation ranged between 0.6 and 0.9 ( 0.7 for a lifestyle question).

\section{Independent variable}

Considering the objectives of this study the independent variable was defined by the following questions: "Has a doctor or health professional ever said that you have diabetes?"; and "Has a doctor or health professional ever said that you have hypertension (high blood pressure)?". The answers to both questions were grouped, and the exposure variable was established: diagnosed with DM and/or SAH (yes/no). 


\section{Dependent variables}

Variables related to healthy and unhealthy dietary practices were collected based on a semiquantitative food questionnaire including 18 questions on weekly and daily frequency of food consumption, in accordance with a model used in a Brazilian nationwide study entitled Surveillance of Risk and Protective Factors for Chronic Diseases on Telephone Interviews [19]. Monteiro et al. research [20] shows that indicators of food consumption used by this system are reproducible (Kappa between 0.6 and 0.8) and compared to three 24-hour recalls, have adequate validity for most indicators (sensitivity and specificity of $\sim 80 \%$ for unhealthy food consumption and $42-80 \%$ for healthy food consumption). Based on these questions the following dichotomous variables of healthy food consumption (yes/no) were determined: regular consumption of fruit, regular consumption of vegetables, daily intake of $\geq 3$ times/day of fruit and; daily consumption of $\geq 2$ times/day of vegetables [21]. Positive diagnosis of these four variables referred to six or more days/week, and the two regular consumption variables were created regardless of how often these foods were consumed daily. In turn, to assess unhealthy food consumption the following dichotomous variables (yes/no) were used: regular consumption of meat fat (fat of red meat or chicken), regular consumption of fried foods, and; regular consumption of soda with added sugar (all considered as unhealthy foods). Regular unhealthy food consumption referred to the consumption of such foods two or more times/week (daily frequency intake data was not collected). Additionally, it was created a healthy dietary practice score based on the food guide for the Brazilian population [21], considering the above-mentioned matters. A point was scored for the daily consumption of each one of the healthy foods ( $\geq 3$ times/day fruit and $\geq 2$ times/day vegetables) and one point for those who did not eat on $\geq 2$ days/week each of the unhealthy foods (meats fat, fried foods and soft drinks). Thus a scale from zero (no healthy eating behaviour) to five points (complete healthy eating behaviour) was established. For result exhibition and graphs, score points were grouped as follows: $0-1$ point, $2-3$ points, 4-5 points.

There were also considered as possible confounders: age in full years (20-29 years, 30-39 years, 40-49 years and 50-59 years-old), self-reported skin colour (white, dark, black, and other), education level in completed years of study ( $0-8$ years, $9-11$ years and $\geq 12$ years) and per capita income in Reais $(\mathrm{R} \$$ ) (upper tertile $=1300.10$ to 33333.00 ; intermediate tertile $=\mathrm{R} \$ 567.00$ to 1300.00 ; lower tertile $=$ up to $\mathrm{R} \$ 566.90-1 \mathrm{USD}=1.72 \mathrm{R} \$$ in 2009). Considering the evidences of different food habits in men and women [22,23], as well as the different access to health services $[24,25]$, all the analyses were stratified by gender, assuming that this variable is a potential effect modifier in the associations between the disease status and the dietary practices.

Data analysis was conducted using the 11.0 Stata program, always considering the process of cluster sampling and respective sample weights (Stata "svy" command). Descriptive analyses were performed by calculating relative frequencies and their 95\% confidence intervals (95\% CI). Chi-square with Rao-Scott correction was used for bivariate analyses. Venns diagram was used to show the frequency of dietary practices in relation to consumption of healthy and unhealthy food between gender and disease status.

Poisson regression was used to obtain the adjusted frequencies of dietary practices between individuals with or without the diagnosis of DM and/or SAH, throughout the "margin" command in Stata program. All sociodemographic variables with $\mathrm{p}$-value $<0.20$ in the bivariate analysis were included in the adjusted analyses as potential confounders. The value of statistical significance was set at $5 \%$.

The EpiFloripa Adults 2009 project was approved by the Ethics Committee on Human Research of the Federal University of Santa Catarina (UFSC), under protocol number 351/08. The subjects were informed about the objectives of the study and were requested to sign an Informed Consent Form.

\section{Results}

A total of 1720 adults ( $85.3 \%$ of the estimated sample) were effectively enrolled in the study. Most of the sample was female $(55.8 \%)$, with white skin colour $(84.2 \%)$ and had a mean of 38 years of age $(\mathrm{SD}=11.6 ; 31.4 \%$ aged from 29 to 39 years). No differences were found between genders for socioeconomic variables (Table 1).

With regard to the consumption of unhealthy food, in the overall sample more than $50.0 \%$ reported a regular consumption of fried foods (51.0\%) and soda (57.9\%). For meat fat, consumption was less frequent (27.7\%). About the consumption of healthy foods, only $42.6 \%$ of the sample consumed fruit in a regular basis, while fruit consumption $\geq 3$ times/day was found in $11.1 \%$. In the case of vegetables, $80.0 \%$ reported consuming $\geq 6$ times/ week and $66.9 \%$ said they ate $\geq 2$ servings/day (data not shown). Unhealthy food consumption was more common in men, while healthy food consumption was more frequent in women ( $\mathrm{p}<0.001$ for all analyses) (Table 1). In turn, the prevalence of DM was $3.7 \%$ and SAH $14.8 \%$, whereas the diagnosis of DM and/or SAH was confirmed by $16.6 \%$ of participants (no gender difference, $\mathrm{p}=0.719)$.

In Figure 1, the Venn diagram shows the frequency of dietary practices in relation to consumption of healthy food (consumption of $\geq 2$ times/day of vegetables and $\geq 3$ times/day of fruit), depending on the health status of individuals (with or without DM and/or SAH), according to gender. Only $5.0 \%$ of healthy men and $11.0 \%$ of healthy 
Table 1 Sociodemographic and dietary practices variable description of 20-59 year-old adults from the EpiFloripa survey, stratified by gender $(n=1720)$

\begin{tabular}{|c|c|c|c|c|}
\hline \multirow[b]{2}{*}{ Variable } & \multicolumn{2}{|c|}{ Male $(n=761)$} & \multicolumn{2}{|c|}{ Female $(n=959)$} \\
\hline & $\bar{n}$ & $\%(\mathrm{Cl} 95 \%)$ & $n$ & $\%(\mathrm{Cl} 95 \%)$ \\
\hline \multicolumn{5}{|l|}{ Age in years } \\
\hline 20 to 29 & 260 & $34.2(30.7 ; 37.5)$ & 280 & $29.2(26.3 ; 32.1)$ \\
\hline 30 to 39 & 172 & $22.6(19.6 ; 25.6)$ & 220 & $22.9(20.3 ; 25.6)$ \\
\hline 40 to 49 & 181 & $23.8(20.8 ; 26.8)$ & 257 & $26.7(24.0 ; 29.6)$ \\
\hline 50 to 59 & 148 & $19.4(16.6 ; 22.3)$ & 202 & $21.1(18.5 ; 23.6)$ \\
\hline \multicolumn{5}{|l|}{ Self-reported skin colour ${ }^{a}$} \\
\hline White & 642 & $84.5(81.9 ; 87.1)$ & 802 & $84.0(81.6 ; 86.3)$ \\
\hline Dark & 74 & $9.7(7.6 ; 11.8)$ & 73 & $7.6(6.0 ; 9.3)$ \\
\hline Black & 34 & $4.5(3.0 ; 5.9)$ & 53 & $5.5(4.1 ; 7.0)$ \\
\hline Other & 10 & $1.3(0.5 ; 2.1)$ & 27 & $2.8(1.7 ; 3.9)$ \\
\hline \multicolumn{5}{|c|}{ Per capita family income (tertiles) ${ }^{a}$} \\
\hline First tertile (Rich) & 258 & $34.6(31.2 ; 38.6)$ & 301 & $32.0(29.0 ; 35.0)$ \\
\hline Second tertile (Intermediate) & 258 & $34.6(31.2 ; 38.6)$ & 304 & $32.3(29.3 ; 35.3)$ \\
\hline Third tertile (Poor) & 229 & $30.7(27.4 ; 34.1)$ & 335 & $35.6(32.6 ; 38.7)$ \\
\hline \multicolumn{5}{|l|}{ Education level in years ${ }^{a}$} \\
\hline 12 or more & 318 & $41.9(38.4 ; 45.5)$ & 419 & $43.7(40.6 ; 46.9)$ \\
\hline 9 to 11 & 263 & $34.7(31.3 ; 38.1)$ & 305 & $31.8(28.9 ; 34.8)$ \\
\hline 0 to 8 & 177 & $23.3(20.3 ; 26.4)$ & 234 & $24.4(21.7 ; 27.2)$ \\
\hline \multicolumn{5}{|l|}{ Regular fruit consumption ${ }^{b}$} \\
\hline Yes & 245 & $32.2(28.9 ; 35.6)$ & 487 & $50.1(47.7 ; 54.0)$ \\
\hline No & 515 & $67.8(64.4 ; 71.1)$ & 471 & $49.1(46.0 ; 52.3)$ \\
\hline \multicolumn{5}{|c|}{ Regular vegetable consumption ${ }^{a, b}$} \\
\hline Yes & 547 & $75.4(72.4 ; 78.5)$ & 802 & $83.7(81.4 ; 86.1)$ \\
\hline No & 187 & $24.6(21.5 ; 27.6)$ & 156 & $16.3(13.9 ; 18.6)$ \\
\hline \multicolumn{5}{|c|}{ Fruit consumption $\geq 3$ times/day ${ }^{a, b}$} \\
\hline Yes & 51 & $6.7(4.9 ; 8.5)$ & 139 & $14.5(12.3 ; 16.7)$ \\
\hline No & 709 & $93.3(91.5 ; 95.1)$ & 819 & $8.5(83.2 ; 87.7)$ \\
\hline \multicolumn{5}{|c|}{ Vegetable consumption $\geq 3$ times/day ${ }^{a, b}$} \\
\hline Yes & 462 & $60.8(57.3 ; 64.3)$ & 686 & $71.7(68.8 ; 74.5)$ \\
\hline No & 298 & $39.2(35.7 ; 42.7)$ & 271 & $28.3(25.5 ; 31.2)$ \\
\hline \multicolumn{5}{|c|}{ Regular fat of meat consumption ${ }^{a, c, d}$} \\
\hline No & 484 & $63.7(60.2 ; 67.1)$ & 758 & $79.1(76.5 ; 81.7)$ \\
\hline Yes & 276 & $36.3(32.9 ; 39.7)$ & 200 & $20.9(18.2 ; 23.5)$ \\
\hline \multicolumn{5}{|c|}{ Regular fried food consumption ${ }^{\mathrm{a}, \mathrm{c}}$} \\
\hline No & 300 & $39.4(35.9 ; 42.9)$ & 539 & $56.4(53.2 ; 59.5)$ \\
\hline Yes & 461 & $60.6(57.1 ; 64.1)$ & 417 & $43.6(40.5 ; 46.8)$ \\
\hline \multicolumn{5}{|c|}{ Regular sugar-sweetened soda consumption ${ }^{a, c}$} \\
\hline No & 282 & $37.1(33.6 ; 40.5)$ & 442 & $46.2(43.0 ; 49.4)$ \\
\hline Yes & 479 & $62.9(59.5 ; 66.4)$ & 515 & $53.8(50.6 ; 57.0)$ \\
\hline
\end{tabular}


Table 1 Sociodemographic and dietary practices variable description of 20-59 year-old adults from the EpiFloripa survey, stratified by gender $(n=1720)$ (Continued)

\begin{tabular}{lllll}
\hline Self-reported DM and/or SAH diagnosis $^{\mathbf{a}}$ & & & & \\
No & 632 & $83.0(80.4 ; 85.7)$ & 801 & $83.7(81.3 ; 86.0)$ \\
Yes & 129 & $17.0(14.3 ; 19.6)$ & 156 & $16.3(14.0 ; 18.6)$
\end{tabular}

DM - diabetes mellitus; SAH - systemic arterial hypertension.

${ }^{a}$ Variables with missing data at most $0.3 \%$, except for per capita family income (2\%).

$b_{\geq} 6$ times/week consumption.

$c^{c} \geq 2$ times/week consumption.

dincludes red meat fat and/or chicken skin.

women consumed both, fruit and vegetables; whereas among those with DM and/or SAH the respective frequencies were $5.0 \%$ and $18.0 \%$. In turn, $38.0 \%$ of healthy men and $26.0 \%$ of healthy women reported not consuming adequate daily frequency of either food; while $33.0 \%$ of male and $26.0 \%$ of female diagnosed with DM and/or
SAH showed the same pattern $(P=0.62$ for men and $\mathrm{P}=0.08$ for women).

Regarding unhealthy food dietary practices, the Venn graph (Figure 2) shows that $15.0 \%$ of healthy men and $28.0 \%$ of healthy women, as well as $22.0 \%$ and $30.0 \%$ of the diagnosed participants had proper dietary practices

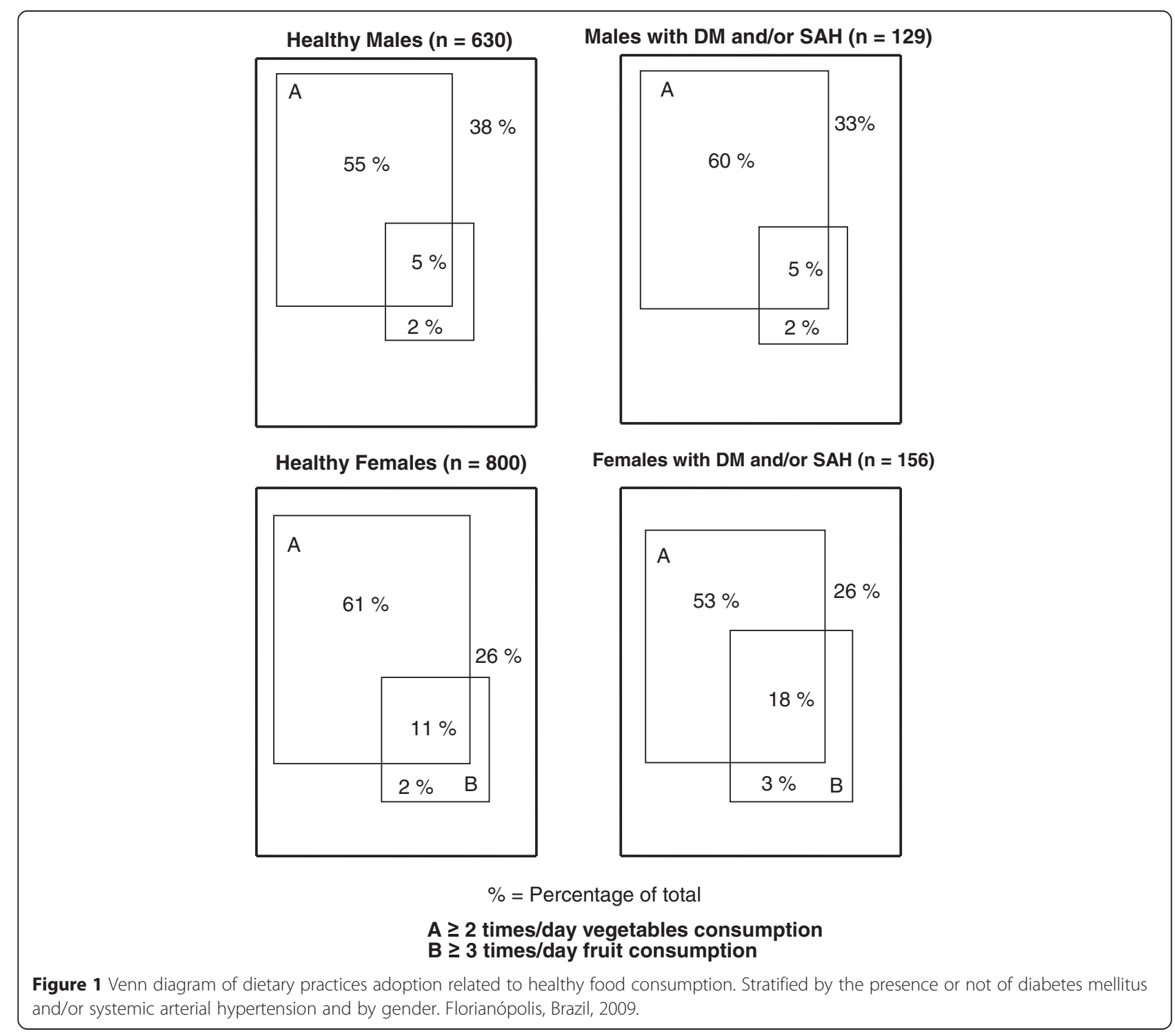




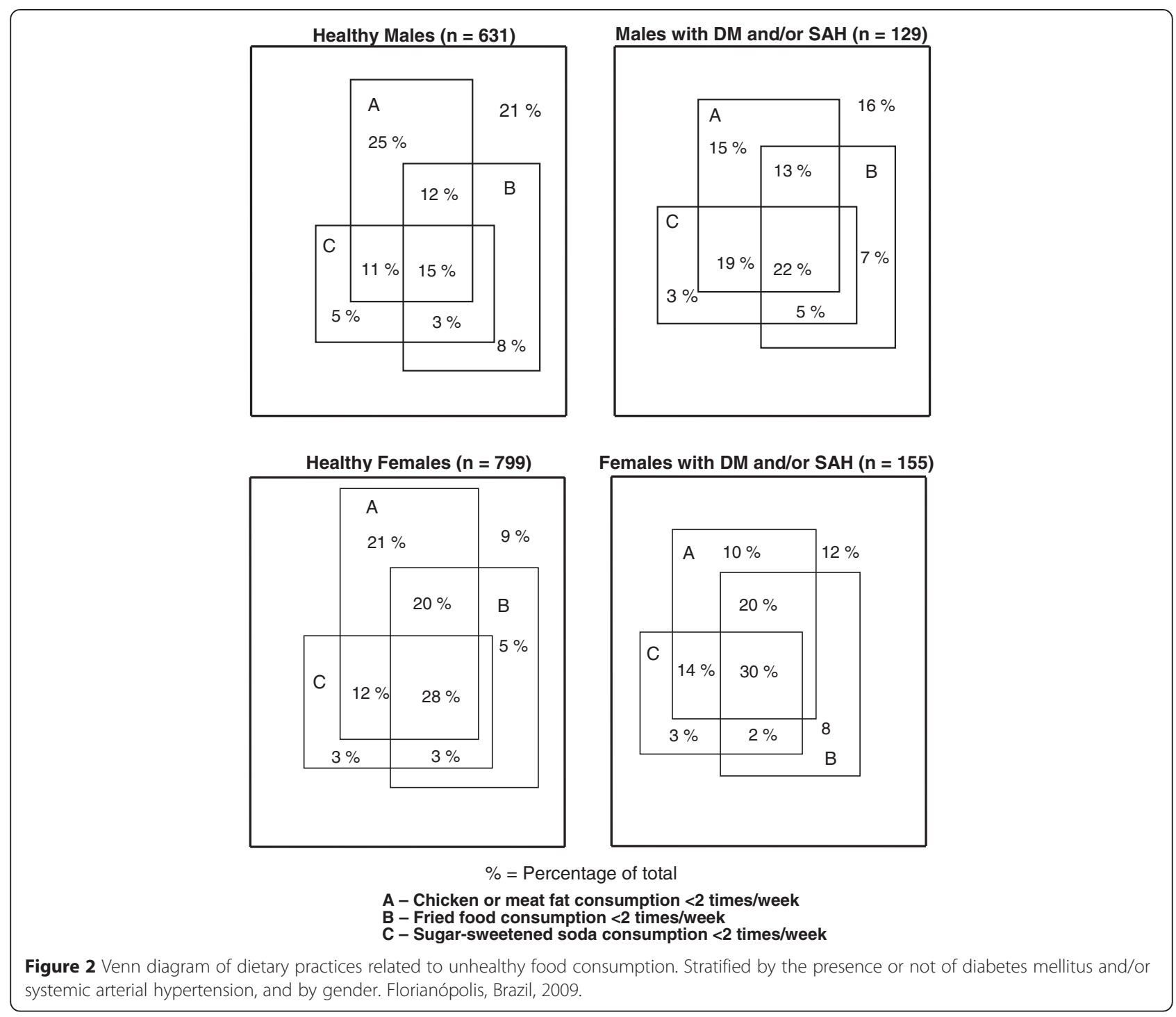

for these types of food, respectively. On the other hand, $21.0 \%$ of healthy men and $9 \%$ of healthy women reported consuming $\geq 2$ times/week each unhealthy food (meat fat, fried foods and/or soft drinks), while the diagnosed participants reported 16 and $12 \%$, respectively $(\mathrm{P}=0.12$ for men and $\mathrm{P}=0.25)$.

Figure 3 shows the scale of healthy dietary practices of respondents (consumption $\geq 3$ times/day of fruit, $\geq 2$ times/day of vegetables and consumption of at most 1 time/week meat fat, fried foods and/or soft drinks). The frequency of 4-5 healthy dietary practices was greater in women compared to men, regardless of whether or not they had DM and/or SAH (14.0\% higher in healthy women compared to healthy men, and almost $15.0 \%$ higher in women with DM and/or SAH when compared to diagnosed men). Still, the frequency of 4-5 healthy dietary practices was not greater than $35 \%$, even in females. In men, almost $87.0 \%$ of healthy individuals and
81.1\% of diagnosed individuals showed a $0-3$ healthy dietary practices rate, while women showed $71.6 \%$ and $66.2 \%$ (15.4\% and $14.9 \%$ greater for men, respectively). Although gender differences were significant $(\mathrm{p}<0.05)$, no differences were found for the number of dietary practices between healthy and diagnosed men and women ( $p>0.10$ in both cases).

Table 2 shows the crude and adjusted association between the presence or not of DM and/or SAH (exposure) and healthy/unhealthy dietary practices variables (outcome). In men, only the regular consumption of fried foods and soft drinks were lower in individuals with DM and/or SAH (17.0\% and 21.0\% lower, respectively) compared with healthy subjects. However, the association was completely confounded by sociodemographic variables. Among woman, in crude analysis, proper fruit consumption was $63.0 \%$ greater among those with DM and/or SAH than among healthy subjects, but this 


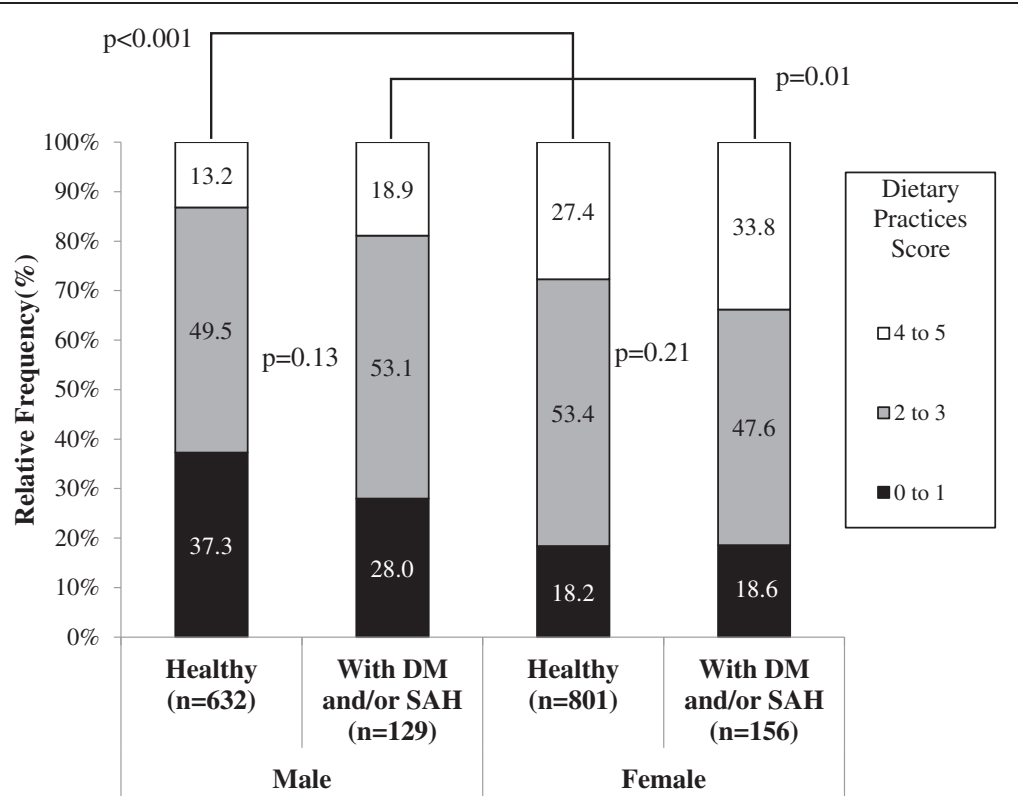

Figure 3 Dietary practices score of 20-59 year-old males and females living in Florianópolis, Brazil, 2009. Stratified by the presence or not of diabetes mellitus and/or systemic arterial hypertension, and by gender.

Table 2 Crude and adjusted analysis of food consumption among people with and without chronic diseases (diabetes mellitus and/or hypertension) in adults aged 20-59 years included in the EpiFloripa study

\begin{tabular}{|c|c|c|c|c|c|c|c|}
\hline & \multirow{3}{*}{$\begin{array}{l}\text { Analysis } \\
\text { type }\end{array}$} & \multicolumn{3}{|l|}{ Male } & \multicolumn{3}{|l|}{ Female } \\
\hline & & $\begin{array}{l}\text { Healthy } \\
(n=632)\end{array}$ & $\begin{array}{l}\text { With DM and/or } \\
\text { SAH }(n=129)\end{array}$ & $\begin{array}{l}\mathrm{p} \\
\text { value }\end{array}$ & $\begin{array}{l}\text { Healthy } \\
(n=801)\end{array}$ & $\begin{array}{l}\text { With DM and/or } \\
\text { SAH }(n=156)\end{array}$ & $\begin{array}{l}p \\
\text { value }\end{array}$ \\
\hline & & $\%(\mathrm{Cl} 95 \%)$ & $\%(\mathrm{Cl} 95 \%)$ & & $\%(\mathrm{Cl} 95 \%)$ & $\%(\mathrm{Cl} 95 \%)$ & \\
\hline \multirow[t]{2}{*}{ Regular fruit consumption $^{a}$} & Crude & $30.4(26.1-35.2)$ & $39.8(31.3-48.9)$ & 0.06 & $48.2(44.3-52.3)$ & $58.5(51.4-65.2)$ & 0.007 \\
\hline & Adjusted* & $32.0(27.9-36.1)$ & $32.2(24.7-39.7)$ & 0.96 & $50.4(46.7-54.1)$ & $48.3(42.4-54.1)$ & 0.51 \\
\hline \multirow[t]{2}{*}{ Regular vegetable consumption ${ }^{a}$} & Crude & $82.4(78.2-86.0)$ & $81.0(73.0-87.0)$ & 0.71 & $72.0(68.0-75.7)$ & $73.9(65.8-80.7)$ & 0.64 \\
\hline & Adjusted* & $82.0(78.5-85.5)$ & $82.9(76.3-89.4)$ & 0.82 & $71.3(67.9-74.7)$ & $76.5(69.1-84.0)$ & 0.23 \\
\hline \multirow[t]{2}{*}{ Daily fruit consumption ( $\geq 3$ times/day) ${ }^{a}$} & Crude & $6.1(4.2-8.7)$ & $6.9(3.8-12.3)$ & 0.70 & $12.6(10.2-15.6)$ & $20.6(15.2-27.2)$ & 0.007 \\
\hline & Adjusted* & $6.4(4.2-8.7)$ & $6.2(2.2-1.0)$ & 0.92 & $13.2(10.7-15.7)$ & $16.4(11.3-21.5)$ & 0.25 \\
\hline \multirow[t]{2}{*}{ Daily vegetable consumption ( $\geq 2$ times/day) ${ }^{a}$} & Crude & $59.2(54.4-63.9)$ & $63.7(55.9-70.9)$ & 0.32 & $71.4(67.1-75.3)$ & $72.8(66.1-78.6)$ & 0.70 \\
\hline & Adjusted* & $61.8(57.8-65.7)$ & $56.2(49.5-62.9)$ & 0.14 & $71.9(68.4-75.3)$ & $67.9(61.3-74.5)$ & 0.29 \\
\hline \multirow[t]{2}{*}{ Regular fat of meats consumption ${ }^{b, c}$} & Crude & $25.4(20.9-30.5)$ & $25.9(19.0-34.2)$ & 0.90 & $10.8(8.7-13.3)$ & $17.0(11.4-22.7)$ & 0.02 \\
\hline & Adjusted* & $26.1(21.7-30.6)$ & $23.8(17.3-30.4)$ & 0.50 & $10.8(8.7-13.0)$ & $15.4(9.8-21.0)$ & 0.09 \\
\hline \multirow[t]{2}{*}{ Regular fried food consumption ${ }^{b}$} & Crude & $62.3(58.6-65.9)$ & $51.4(43.1-59.6)$ & 0,016 & $44.3(40.8-47.9)$ & $40.3(32.9-48.3)$ & 0.33 \\
\hline & Adjusted* & $60.2(56.3-64.1)$ & $57.4(48.2-66.8)$ & 0.60 & $42.6(39.3-46.0)$ & $47.4(38.4-56.5)$ & 0.31 \\
\hline \multirow[t]{2}{*}{ Regular sugar-sweetened Soda consumption ${ }^{\text {b }}$} & Crude & $64.8(59.0-70.2)$ & $51.5(42.9-60.0)$ & 0,006 & $54.0(49.2-56.8)$ & $49.8(41.1-58.5)$ & 0.34 \\
\hline & Adjusted* & $63.2(58.3-68.1)$ & $58.2(49.6-66.7)$ & 0.34 & $53.0(49.2-56.8)$ & $55.5(47.1-63.9)$ & 0.61 \\
\hline
\end{tabular}

Stratified by gender.

${ }^{a} \geq 6$ times/week consumption.

$b^{b} 2$ times/week consumption.

'Includes red meat fat and/or chicken skin.

*Adjusted for skin colour, age, per capita family income and education level. 
association disappeared after adjustment. And contrary to expected, consumption of meat fat was $57.0 \%$ greater among those diagnosed with DM and/or SAH compared with healthy individuals. However, this association became nonsignificant after adjustment for confounders. None of the other variables of consumption was associated with disease condition for both genders, neither in crude or adjusted analysis.

\section{Discussion}

This paper assessed in a population-based sample whether the different dietary practices - which are essential in the treatment and prevention of DM and SAH consequences $[2,12,26]$ - were more frequent among people diagnosed with such NCDs, in comparison with the rest of the population. Based on the results, three main conclusions can be highlighted. First, whether in relation to healthy or unhealthy food consumption, healthier dietary practices were more frequent in women than men. Second, no differences were found for dietary practices when comparing those diagnosed with DM and/or SAH with the rest of the sample, even among women. Third, the few results that pointed to better dietary practices of individuals with DM and/or SAH compared to healthy individuals were completely confounded by sociodemographic variables, especially after adjustment for education level. Therefore, our results suggest that sociodemograhic variables, in particular education level, are more important for dietary practices than the presence of DM and/or SAH. This is particularly relevant for public health promotion, as previous studies have also shown that gender, family income and education level are deeply related to food habits [23,27-29]. The lower the income and education level, the lower the daily intake of fruits and vegetables, and the higher the consumption of fatty foods. Additionally, socioeconomic position and gender are also related to health services access, and in consequence, to the diagnosis and treatment of chronic diseases [24].

In this study, women consumed fruit and vegetables more frequently, and had a lower intake of meat fat, fried foods and soft drinks compared to men. This result is consistent with evidence from previous studies showing that women not only take more care on their dietary practices, but also have a higher utilization of health care services when compared to men [22-24]. Even the increased demand for health services may result in greater diagnosis for women (detection bias); prevalence rates of both NCDs combined were similar in both genders, which reduces the probability that this bias has affected the results. Nevertheless, the matters listed above justify the need for stratification of analyses by gender.

In turn, the use of individual's report on the diagnosis of DM and/or SAH may underestimate the actual prevalence of these diseases, considering that this type of self- reported information has approximately $70 \%$ sensitivity and $90 \%$ specificity [30]. In our study, prevalence rates for both diseases (3.7\% for DM and 14.8\% for hypertension) were lower than available estimates to this age group (6-7\% and 30\%, respectively) [31]. Nevertheless, it is unlikely that these underestimates affected the association of diseases with the different dietary practices, since changes in food intake would be expected only among individuals that were aware of their diagnosis.

Several international $[2,4,13]$ and Brazilian entities [6] recommend a diet rich in fruits and vegetables, low in saturated and total fat, and reduced consumption of sugary drinks, as primary and secondary prevention measures in fighting against obesity and NCDs. Healthy dietary practices may be responsible for a reduction of up to $5-6 \mathrm{~mm} \mathrm{Hg}$ in systolic and up to $3 \mathrm{mmHg}$ diastolic [13] blood pressure, and may help to reduce the conversion rates of insulin resistance to type 2 diabetes by up to $43 \%$ in a period of twenty years [2,14]. Despite this evidence, and that the existing recommendations should be followed by the entire population, three of the healthy dietary practices examined have much lower frequency than expected, even among people diagnosed with DM and/or SAH. In both genders and regardless of disease condition, the frequency of daily fruit intake did not exceed $20 \%$. In turn, regular consumption of fried foods and sodas ranged from 40-60\% (higher in men than in women). This scenario has also been evidenced in high-income countries. The NHANES study, conducted in the United States with 7,811 40-74 year-old individuals, assessed from 2001-2006, showed that only $26 \%$ of participants consumed five or more servings of fruits and vegetables, and individuals with history of DM, SAH and/or cardiovascular disease showed no differences in dietary practices compared to healthy subjects [32].

These percentages above are worrisome, considering the changes in the profile of food habits for the Brazilian population. When assessing the changes in the consumption of sodas in state capitals, data from the Survey of Family Budgets (Pesquisa de Orçamentos Familiares) [33] shows that, among the surveys of 2002-2003 and 2008-2009 there was a 39\% increase in the purchase of these products in the urban area and 92\% in rural areas. In the same period, despite an increase of $17.9 \%$ on purchases of fruits, vegetables decreased by approximately two kilograms per capita. In addition, the lack of healthy dietary practices affects not only the individuals, but the entire Brazilian health system. Brazil estimates a total spend of US\$ 398.9 million every year for the treatment of hypertension in the public health system, which represents $1.43 \%$ of the total expenditures of the Unified Health System (SUS) [10]. These costs are even greater when considering the associated complications, such as cardiovascular disease. The latter have accounted 
for almost 1.2 million hospitalizations in Brazil in 2005, which cost US\$ 546.6 million to the Brazilian government [10].

The low frequency of healthy dietary practices mentioned in this study was also evident when consumption was analysed in a healthy dietary practices score. Only $13.2 \%$ of men and $33.8 \%$ of women had $4-5$ points, with no difference between healthy and DM and/or SAH diagnosed groups. A cross-sectional population-based study conducted in the United States assessed the adequacy of Dietary Approaches to Stop Hypertension (DASH) in 5,867 adults, considering a score of up to nine points [15]. That study found no difference in dietary practices among people without DM, with DM and SAH or only with DM.

Several interventions to encourage the consumption of healthy foods, as well as other health care actions have been carried out, but showed poor results, often improving the knowledge, but not the healthy behaviours [34]. On the other hand, the literature also indicates deficiency in the quality of information passed on by health professionals to $\mathrm{DM}$ and/or SAH patients in relation to lifestyle changes. While treatment guidelines for these diseases do recommend changes in lifestyle as the first therapeutic measure for secondary prevention, health professionals use the prescription of antihypertensive medications and/or hypoglycemic agents as initial treatment for these patients $[35,36]$.

According to Santos \& Victora [37], the reasons for the low effectiveness in primary health care include a long causal chain that starts in carrying out interventions and ends on their consequences, the functioning of the health system (access, availability of supplementary exams and drugs), besides environmental, cultural, demographic and epidemiological matters. Meanwhile, developing healthy dietary practices is a difficult task, because unhealthy habits are associated with feelings of pleasure, and are widely disseminated in the media, and they show harmful effects in a slow and quiet manner $[1,38]$.

Some national actions and policies have been developed with the intent of modifying eating habits and reducing the prevalence of NCDs in the Brazilian population, such as the "Strategic Action Plan for the Fight Against NCDs in Brazil , 2011-2022" released by the Ministry of health in 2011 [26] and the "National Food Policy at School", which encourage healthy eating habits from the earliest years of life [39]. Such initiatives are critical for the success of the primary and secondary prevention of these diseases and other NCDs, considering the need for early guidance on these issues. It is also crucial to educate different sectors of society about the importance of dietary practices, expanding the reach of prevention and reducing the development of NCDs and their complications. Further research is needed to assess the effectiveness of these policies on health, not only in relation to the prevalence of these diseases, but also in changing the lifestyle of the population.

A possible limitation of this study was the use of a semiquantitative questionnaire to assess dietary practices, even though it was based on an instrument employed in periodic national surveys regarding the health status of the population [19]. Another limitation related to dietary practices is the lack of analysis of other foods considered harmful for the diseases investigated, such as processed and ultra-processed foods (high in sodium, saturated fat and sugars). Finally, the crosssectional design used in the study doesn't allow drawing conclusions about the cause-effect between the NCDs diagnosis and changes in dietary practices. However, this study based on a representative sample of the population of Florianópolis is important, as it allows to reproduce the population structure of the municipality, ensuring the external validity of the research. Moreover, several procedures were adopted in this study to improve data quality, both in data collection and analysis.

\section{Conclusions}

To conclude, our results showed low frequency of healthy dietary practices for both healthy and DM and/ or SAH diagnosed individuals. Even though the lack of healthy dietary practices in the general population is an aggravating factor for the increased prevalence of obesity and NCDs in a middle-income country such as Brazil, it is more worrisome that DM and/or SAH are not associated with healthy dietary practices, since the morbidity and mortality associated with these diseases have a major impact on the individual, their families and society. Thus, the challenge for public health is not only to investigate the reasons for the lack of meticulous care, but also to create health policies and comprehensive educational programs to encourage a change on the eating behaviour of the population.

\section{Abbreviations}

DM: Diabetes mellitus; NCD's: Non-communicable diseases; NHANES: National Health and Nutrition Examination Survey; SAH: Systemic arterial hypertension; SUS: Unified Health System; WHO: World Health Organization.

\section{Competing interests}

The authors declare that they have no competing interests.

\section{Authors' contributions}

SGIO has conducted the statistical analyses, written and led this article. COB has participated in the study design and field supervision, contributed in writing the discussion of the data and revising it. FC has contributed to writing and revising this article. MP led the EpiFloripa research and contributed to the revision of this article.DAG contributed to the study design, statistical analysis, writing, and revision. All authors read and approved the final manuscript.

\section{Acknowledgements}

We thank Dr. Nilza Nunes da Silva, Department of Epidemiology, School of Public Health of University of São Paulo, São Paulo, Brazil, for her advice on 
sample procedures. We would like to thank the Brazilian Institute of Geography and Statistics (IBGE) and the Florianópolis Health Authority staff for their useful help with the practical aspects of the study. All authors have conceived and designed the study, performed the experiments, analyzed the data and written the paper.

\section{Financial support}

The Project was sponsored by the Brazilian National Council for Scientific and Technological Development (CNPq), grant number 485327/2007-4.

\section{Author details}

${ }^{1}$ Post-Graduate Program in Public Health, Federal University of Santa Catarina, 88040-970 Florianópolis, SC, Brazil. ${ }^{2}$ Australian Research Centre for Population Oral Health. School of Dentistry, The University of Adelaide, Adelaide, South Australia, Australia. ${ }^{3}$ Post-Graduate Program in Nutrition, Federal University of Santa Catarina, Florianópolis, SC, Brazil.

\section{Received: 24 September 2014 Accepted: 24 April 2015 Published online: 10 May 2015}

\section{References}

1. Popkin BM, Adair LS, Ng SW. Global nutrition transition and the pandemic of obesity in developing countries. Nutr Rev. 2012;70(1):3-21.

2. American Diabetes Association. Standarts of medical care in diabetes-2013. Diabetes Care. 2013;36:S11-66.

3. World Health Organization. World Health Statistics 2012. Geneva: World Health Organization; 2012.

4. World Health Organization. Diet, Nutrition and the Prevention of Chronic Diseases. Joint WHO/FAO Expert Consultation. WHO Technical Report Series no. 916. Geneva: WHO; 2003.

5. Brasil. Ministério da Saúde. Secretaria de Vigilância em Saúde. Secretaria de Gestão Estratégica e Participativa. Vigitel Brazil 2011: Protective and Risk Factors for Chronic Diseases by Telephone Survey. In: Ministério da Saúde, Secretaria de Vigilância em Saúde, Secretaria de Gestão Estratégica e Participativa. Brasília: Ministério da Saúde; 2012

6. SBC, SBH, SBN. Sociedade Brasileira de Cardiologia, Sociedade Brasileira de Hipertensão, Sociedade Brasileira de Nefrologia: VI Diretrizes Brasileiras de Hipertensão Arteria. Arq Bras Cardiol. 2010;1(1):1-51.

7. World Health Organization: Noncommunicable diseases 2011 [http://gamapserver.who.int/mapLibrary/app/searchResults.aspx]

8. World Health Organization: Diabetes: the cost of Diabetes 2010 [http://www.who.int/mediacentre/factsheets/fs236/en/]

9. Barreto SM, Pinheiro ARO, Sichieri R, Monteiro CA, Filho MB, Schmidt MI, et al. Analysis of the global strategy on diet, physical activity and health of the World Health Organization. Epidemiol Serv Saúde. 2005;14(1):41-68.

10. Dib MW, Riera R, Ferraz MB. Estimated annual cost of arterial arterial hypertension treatment in Brazil. Rev Panam Salud Publica. 2010;27:125-31.

11. Rosa RS, Schmidt MI. Diabetes Mellitus: magnitude das hospitalizações na rede pública do Brasil, 1999-2001. Epidemiol Serv Saude. 2008;17(2):131-4.

12. World Health Organization. Preventing chronic diseases a vital investment Geneva: World Health Organization; 2005.

13. Eckel RH, Jakicic JM, Ard JD, Jesus JM, Lee I, Lichtenstein AH, et al. AHA/ACC Guideline on Lifestyle Management to Reduce Cardiovascular Risk: A Report of the American College of Cardiology/American Heart Association Task Force on Practice Guidelines. Circulation 2013.

14. Gillett M, Royle P, Snaith A, Scotland G, Poobalan A, Inamura M, et al. Non-pharmacological interventions to reduce the risk of diabetes in people with impaired glucose regulation: a systematic review and economic evaluation. Health Technol Assess. 2012;16:33.

15. Morton S, Saydah S, Cleary SD. Consistency with the dietary approaches to stop hypertension diet among adults with diabetes. J Acad Nutr Diet. 2012;112(11):1798-805.

16. Instituto Brasileiro de Geografia e Estatística (IBGE): Contagem da população. Rio de Janeiro: IBGE 2000 [http://www.ibge.gov.br/home/]

17. IBGE. Instituto Brasileiro de Geografia e Estatística: Taxa de analfabetismo da população de 15 anos ou mais de idade, por grupos de idade, segundo as Unidades da Federação e os municípios das capitais 2000/2010. Rio de Janeiro; 2011.

18. Boing AC, Peres KG, Boing AF, Hallal PC, Silva NN, Peres MA. EpiFloripa Health Survey: the methodological and operational aspects behind the scenes. Rev Bras Epidemiol. 2014;17(1):146-62.
19. Souza AM, Bezerra IN, Cunha DB, Sichieri R. Evaluation of food intake markers in the Brazilian surveillance system for chronic diseases - VIGITEL 2007-2009. Rev Bras Epidemiol. 2011;14(1):44-52

20. Monteiro CA, Moura EC, Jaime PC, Claro RM. Validity of food and beverage intake data obtained by telephone survey. Rev Saude Publica. 2008:42(4):582-9.

21. Brasil. Ministério da Saúde. Secretaria de Atenção à Saúde. Coordenação Geral da Política de Alimentação e Nutrição: Guia alimentar para a população brasileira: promovendo a alimentação saudável. Ministério da Saúde, Secretaria de Atenção à Saúde, Coordenação-Geral da Política de Alimentação e Nutrição. Brasília: Ministério da Saúde; 2005.

22. Piernas C, Popkin BM. Snacking increased among U.S. Adults between 1977 and 2006. J Nutr. 2010;140((2):325-32

23. Wardle J, Haase AM, Steptoe A, Nillapun M, Jonwutiwes K, Belliste F. Gender differences in food choice: the contribution of health beliefs and dieting. Ann Behav Med. 2004;27(2):107-16.

24. Assada Y, Kephart G: Equity in health services use and intensity of use in Canada. BMC Health Serv Res 2007, 7-41.

25. Pinkhasov R, Wong J, Kashanian J, Lee M, Samadi DB, Pinkhasov MM, et al. Are men shortchanged on health? Perspective on health care utilization and health risk behavior in men and women in the United States. Int J Clin Pract. 2010;64(4):475-87.

26. Brasil. Ministério da Saúde. Secretaria de Vigilância em Saúde. Departamento de Análise de Situação de Saúde: Plano de ações estratégicas para o enfrentamento das doenças crônicas não transmissíveis (DCNT) no Brasil 2011-2022. Ministério da Saúde. Secretaria de Vigilância em Saúde. Departamento de Análise de Situação de Saúde. Brasília: Ministério da Saúde; 2011.

27. Darmon N, Drewnowski A. Does social class predict diet quality? Am J Clin Nutr. 2008;87(5):1107-17.

28. Arruda SP, Silva AA, Kac G, Goldani MZ, Bettiol H, Barbieri MA. Socioeconomic and demographic factors are associated with dietary patterns in a cohort of young Brazilian adults. BMC Public Health. 2014;14:654.

29. Loureiro AS, Silva RMVG, Rodrigues PRM, Pereira RA, Wendpap LL, Ferreira MG. Diet quality in a sample of adults from Cuiabá (MT), Brazil: association with sociodemographic factors. Rev Nutr. 2013;26(4):431-41.

30. Okura Y, Urban LH, Mahoney DW, Jacobsen SJ, Rodeheffer RJ. Agreement between self-reported questionnaires and medical record data was substantial for diabetes, hypertension, myocardial infarction and stroke but not for heart failure. J Clin Epidemiol. 2004;57:1096-103.

31. Kearney PM, Whelton M, Reynolds K, Whelton PK, He J. Worldwide prevalence of hypertension: a systematic review. J Hypertens. 2004;22(1):11-9.

32. King DE, Mainous III AG, Carnemolla M, Everett CJ. Adherence to healthy lifestyle habits in US adults. Am J Med. 2009;122:528-34.

33. Levy RB, Claro RM, Mondini L, Sichieri R, Monteiro CA. Regional and socioeconomic distribution of household food availability in Brazil in 2008-2009. Rev Saude Publica. 2012;46(1):6-15.

34. Desroches S, Lapointe A, Ratté S, Gravel K, Légaré F, Turcotte S: Interventions to enhance adherence to dietary advice for preventing and managing chronic diseases in adults. Cochrane Database of Systematic Reviews 2013, Issue 2.

35. Cutler JA, Sorlie PD, Wolz M, Thom T, Fields LE, Roccella EJ. Trends in hypertension prevalence, awareness, treatment, and control rates in United States adults between 1988-1994 and 1999-2004. Hypertension. 2008:52:818-27.

36. Capilheira M, Santos IS. Non-communicable chronic diseases: performance of medical care in Primary Health Care in southern Brazil. Cad Saude Publica. 2011;27(6):1143-53.

37. Santos IS, Victora CG. Epidemiology, research, and health services evaluation. Cad Saude Publica. 2004;20(2):337-41.

38. Barreto SM, Passos VMA, Giatti L. Healthy behavior among Brazilian young adults. Rev Saude Publica. 2009:43(2):9-17.

39. Rocha C. Developments in National Policies for Food and Nutrition Security in Brazil. Dev Pol Rev. 2009;27(1):51-66. 